\title{
Recursos electrónicos para la documentación informativa: prensa, audiovisual y publicidad
}

\author{
Juan Francisco Torregrosa Carmona \\ María F. Sánchez Hernández \\ Universidad Rey Juan Carlos (Madrid)
}

\section{Resumen}

Se realiza un "recorrido virtual" por treinta portales españoles y extranjeros analizando herramientas electrónicas y fuentes de información on-line cuya temática principal se centra en la documentación informativa aplicada a la prensa, a los medios audiovisuales y a la publicidad. En concreto, se pretende ofrecer los recursos electrónicos más importantes especializados en documentación de medios de comunicación a través de Internet, y realizar un análisis comparativo entre los recursos seleccionados. La metodología empleada en el análisis y estudio comparativo ha consistido en buscar y localizar los recursos informativos cuya temática principal fuese la documentación periodística, en conocer sus servicios y funciones on-line, además de su difusión, y en realizar un análisis comparativo de los recursos recopilados. El futuro y el presente es multimedia, de forma que prosperarán los sistemas de difusión de documentos basados en realidad virtual; por ello, los resultados de este trabajo proporcionarán una visión de la situación actual de la documentación Informativa en sus distintas facetas en Internet.

Palabras clave: Documentación informativa. Recursos electrónicos. Internet.

\begin{abstract}
Virtual visits at thirty Spanish and foreing web sites, analyzing electronic tools and on-line information sources whose main topic is focused on the information data applied to press, audiovisual means and advertising. The aims are to offer the most important electronic resources specializing in mass media information data throughout Internet, and carry out a comparative analysis between the choice resources. The research has been conducted in three stages: searching and locating the information resources, analyzing the on-line services, their functions and their impact, and carrying out a comparative analysis of the found resources. Not only the future, but also the present is multimedia, so that documentary spreading systems based on virtual reality will prosper. So, the results of this work will
\end{abstract} Scire. 12 : 2 (jul.-dic. 2006) 165-175. ISSN 1135-3716. 
provide a vision of the present situation of the information data in their different sides in Internet.

Key words: Mass media documentation. Electronic resources. Internet.

\section{Introducción}

La documentación como ciencia interdisciplinaria podemos decir que tuvo su origen reciente en el siglo XX. Los factores que determinaron su desarrollo fueron, en primer lugar, la llamada explosión informativa o, lo que es lo mismo, un incremento desmesurado del volumen de información disponible, al mismo tiempo que crecía el consumo y hasta el consumismo de información. No olvidemos que, como siempre se ha creído y se ha repetido reiteradamente, la información es poder. En segundo lugar, otro factor que ayudará sin duda al desarrollo de la documentación será la llegada de las denominadas nuevas tecnologías.

El hecho documental forma parte de la estructura del proceso informativo. El origen de la documentación informativa se basa en la información dentro del contexto de las ciencias de la información y de la documentación.

La documentación informativa como ciencia y actividad documental característica en cualquier medio de comunicación engloba: $a$ ) documentación escrita o textual: eje del trabajo documental que se realiza en un departamento de documentación de cualquier medio de comunicación; el texto se muestra como la única vía de la recuperación de información, independientemente de que esta aparezca en forma de imagen y/o de sonido, ya que la documentación escrita puede aportar credibilidad a lo que se comunica tanto en registros sonoros como de imágenes; b) documentación fotoperiodística: imagen fija; $c$ ) documentación audiovisual: imagen en movimiento más sonido; $e$ ) documentación sonora: sonido; $f$ ) documentación multimedia: unión de las anteriores.

La generalización de Internet como medio de comunicación y plataforma de medios ha hecho que cada vez sea más destacado el papel de la Red como fuente documental de primer orden, gracias una variada tipología de sitios web, que podrá aplicarse tanto para la documentación especializada en la prensa, la televisión o la radio como para la publicidad. En el caso de las imágenes también se comprueba esta realidad notoria. Además de las posibilidades como medio de transmisión, esa otra faceta de inmensa memoria digital se verá incrementada, previsiblemente, con la incorporación de otros muchos documentos accesibles para los diferentes usuarios (Ruiz, 2005).

Las tareas llevadas a cabo por el documentalista de medios de comunicación actual han cambiado: ahora es un gestor de la información, un experto del conocimiento y un tecnólogo, porque toda la cadena documental se está transformando, desde el proceso de selección hasta la difusión de la información. El docu- 
mentalista, en cualquier área de actividad en que trabaje, debe mantenerse actualizado en lo que las nuevas tecnologías pueden aportar a este campo y en lo que se refiere al papel de mediador "interactivo" entre el usuario y las fuentes de información.

Las funciones elementales de los servicios de documentación de medios de comunicación son: $a$ ) proporcionar fuentes concretas para poder comprobar rápidamente un hecho o un dato; $b$ ) aportar materiales para situar los diferentes temas en su contexto; $c$ ) actuar como "fuente de ayuda" con nuevas ideas o nuevos enfoques sobre temas existentes y facilitar datos concretos o generales sobre un tema o ampliar informaciones complementarias.

\section{La documentación en la prensa}

La documentación virtual está presente en cualquier medio de comunicación; se considera como una fuente de información a la que se acude para recabar y contrastar los datos necesarios en la elaboración de noticias completas y documentadas. En los servicios de documentación de medios de comunicación es necesario imponer los objetivos y necesidades dadas las diferentes características generales de los medios.

Los tipos de usuarios que consultan el servicio de documentación de prensa son los siguientes:

1. Periodistas. Necesitan la información para responder a preguntas o dudas de cualquier asunto, o para verificar datos concretos. Estas respuestas se pueden encontrar en la prensa digital, en recursos virtuales, en programas radiofónicos o en forma de dossier o colección.

2. Usuarios de información periodística retrospectiva. Son empresas, organismos o instituciones públicas o privadas que necesitan generalmente información rápida sobre economía, política, sociedad o cultura.

3. Usuarios académicos. Son estudiantes, profesores, investigadores, economistas, sociólogos, etcétera, que precisan datos de la actualidad económica, política..., recientes o a modo retrospectivo, para la realización de un seguimiento o una tesis doctoral, por ejemplo.

4. Resto de usuarios. Estos comportan menos dificultades a la hora de atender sus peticiones: pueden ser preguntas de datos concretos (direcciones de servicios públicos, fechas determinadas...). Aquí el servicio de documentación juega el rol de "servicio pregunta-respuesta".

Los servicios de documentación periodística han de intentar tener la última información rápida y accesible para la respuesta específica, completa y verídica que precise el periodista; en este caso, en Internet muchas veces encontramos la respuesta.

Scire. 12 : 2 (jul.-dic. 2006) 165-175. ISSN 1135-3716. 
En otras ocasiones los periodistas necesitan ampliar información sobre un tema concreto; en este caso, el documentalista debe proporcionarles material (libros, artículos, dossieres...) para la elaboración de una información completa. En ambos casos siempre es recomendable verificar los documentos que se suministran.

El documentalista debe prever las necesidades informativas que le puedan demandar; para ello es necesario que cuente con los instrumentos documentales adecuados.

\subsection{Fuentes y recursos virtuales}

\section{Portal de la Comunicación (www.portalcomunicacion.com)}

Se ha constituido en un portal de referencia para España y los países de habla hispana el llamado Portal de la Comunicación, dependiente del InCom (Instituto de la Comunicación de la Universidad Autónoma de Barcelona) y creado hace un lustro con una orientación particular hacia el mundo latinoamericano, además de hacia Cataluña y el resto de España. A lo largo de su existencia ha contado con ayudas y patrocinios como los de la Fundación Retevisión-Auna y la Generalitat de Catalunya.

Constituye un excelente recurso que ofrece mucho más que los hipervínculos a portales de empresas y otros sitios web de interés. Proporciona buena parte de la tipología de recursos digitales disponibles en la Red, y ello de manera gratuita. Para el acceso a algunos contenidos es preciso registrarse antes. En definitiva, cuenta con unos contenidos actualizados con frecuencia y de contrastada calidad.

\section{Revista Telos (http://www.campusred.net/telos/home.asp?rev=67)}

Esta prestigiosa revista del sector de la comunicación se encuentra en su segunda época. De periodicidad trimestral, está patrocinada por la Fundación Telefónica y alojada en el portal educativo Campus Red, igualmente apoyado por la entidad mencionada. También se puede consultar en la versión impresa tradicional, disponible en librerías especializadas. Entre las aportaciones que hacen posible esta publicación académica y profesional destacan los artículos y las investigaciones presentadas por el profesorado de las distintas facultades universitarias de Información y Comunicación.

\section{Agenda de la Comunicación}

Existe un directorio, buscador y portal para profesionales de los medios de comunicación con la citada denominación (www.agendadelacomunicacion.com). Sin embargo, la Agenda de la Comunicación es desde hace muchos años una publicación oficial que editan los servicios de prensa de la Presidencia del Gobierno a través de la Secretaría de Estado de Comunicación, de la misma manera que lo hace la Oficina del Portavoz del Gobierno u organismos similares de la mayoría de co- 
munidades autónomas del país. Esa guía se publica con carácter anual en forma de libro, pero tiene también su correlato en versión digital, accesible desde la URL http://www.la-moncloa.es/ServiciosdePrensa/Agendadelacomunicacion/default.htm.

De esta forma, se convierte en un instrumento muy útil para los profesionales de la comunicación que pueden consultar esta base de datos, concretamente un directorio nacional muy detallado tanto de empresas informativas como de gabinetes de prensa de los organismos y altas instituciones del Estado.

\section{Journalism.org (www.journalism.org)}

Del ámbito internacional debemos destacar este sitio web, con herramientas para profesionales del periodismo estadounidense, para estudiantes, profesores, entre otros perfiles específicos. Se trata de un recurso auspiciado por un grupo de destacados directores de periódicos y profesionales veteranos y prestigiosos que tratan de mejorar la calidad y la ética en el mundo profesional del periodismo, especialmente en los Estados Unidos: sus impulsores trabajan en el Proyecto para la Excelencia en el Periodismo y conforman el denominado Comité de Periodistas Preocupados (o Concernidos). Las actuaciones de este grupo de trabajo creado en junio de 1997 están teniendo una apreciable difusión no solo en Norteamérica sino también en España y en el resto de Europa. El resultado de varios años de investigaciones y encuentros académicos se publicó en la obra The elements of journalism: what newspeople should know and the public should expect, del que son autores Bill Kovach y Tom Rosenstiel, dos de los fundadores del Comité y su presidente y vicepresidente. Ese valioso libro fue publicado también en español por la editorial Aguilar (grupo Santillana) en el año 2003 en Madrid con el título Los elementos del periodismo.

\section{FELAFACS: Federación Latinoamericana}

de Facultades de Comunicación Social (www.felafacs.org)

En este portal de carácter institucional y universitario que abarca toda la geografía de América Latina podemos encontrar multitud de recursos electrónicos y contenidos de interés. Entre los enlaces que incluye, es digno de destacarse el que nos lleva hacia un sitio web de similar perfil al analizado: se trata de www.infoamerica.org, autodenominado "el espacio iberoamericano de la comunicación".

\section{La documentación en el sector audiovisual}

Según López Yepes, documentación audiovisual es la "ciencia que tiene por objeto el estudio del proceso de comunicación de las fuentes audiovisuales para la obtención de nuevo conocimiento aplicado a la investigación y el trabajo audiovisuales". Para Hernández Pérez, es el "mensaje que, fijado en un soporte óptico, magnético o de cualquier tipo, se presenta en forma de signos icónicos y sonoros

Scire. $12: 2$ (jul.-dic. 2006) 165-175. ISSN 1135-3716. 
de forma más o menos sincrónica, susceptibles de ser reutilizados, en todo o en parte, en la elaboración de nuevos mensajes".

Los objetivos y funciones de los centros de documentación audiovisual, en opinión de López Hernández, son

1. Recopilar y transmitir, a partir del análisis de las fuentes que ingresan en el centro, solo aquella información que sirva para mejorar y activar el trabajo desarrollado en el seno de la organización.

2. Facilitar, en el menor tiempo posible, toda la documentación que requieran los miembros de la organización para realizar con efectividad su trabajo.

3. Asesorar y servir de guía a los usuarios en la búsqueda de fuentes o documentos que no forman parte del archivo propio del centro, indicándoles en tal caso dónde y cómo puede hacerse con esa o esas informaciones que precisa.

El servicio de documentación audiovisual debe contar con documentos multimedia (audiovisuales, fotográficos, textuales periodísticos, sonoros) y, por supuesto, con recursos virtuales con acceso a través de Internet.

\subsection{Fuentes y recursos virtuales}

Dentro del sector audiovisual podemos considerar incluidos, de forma principal, el cine, la televisión y también la radio, aunque su naturaleza sea exclusivamente sonora. Por ello, dada la amplitud temática que cabe considerar incluida en este ámbito, nos centraremos exclusivamente en las posibilidades de información y documentación que ofrece la Red respecto al séptimo arte.

\section{IMDB (www.imdb.com)}

Por lo que tiene que ver con el cine concretamente, existe un sitio web que está considerado como uno de los mejores, si no el mejor, dentro de su género. Se trata de The Internet Movie Database. Esta base de datos tiene indexados más de 500000 títulos entre contenidos cinematográficos y televisivos, películas y series, principalmente. Fue además una de las primeras páginas web especializadas en el séptimo arte. Nació en 1990 como vehículo para el intercambio de resúmenes de filmes y otras informaciones entre cinéfilos. Posteriormente, conforme crecía fue aumentando su carácter comercial y su dominio empresarial. En concreto, a mitad de los años noventa pasaría a ser de titularidad de la potente empresa de venta de productos culturales on-line Amazon.

CineDocNet: Portal de Documentación Cinematográfica (http://multidoc.rediris.es/cinedocnet/index.php)

Actualmente está en fase de actualización, pero cuenta con numerosos y valiosos contenidos que dan lugar a varias áreas en función de su origen, soporte y naturaleza: mediateca, fototeca, hemeroteca, videoteca y fonoteca. La responsabilidad de este recurso recae en un equipo de trabajo de docentes e investigadores 
de la Facultad de Ciencias de la Información de la Universidad Complutense de Madrid.

\section{Buscacine (www.buscacine.com)}

Se trata de un directorio temático de sitios cinematográficos que ofrece la posibilidad de consultar mediante buscador. Ofrece también otros servicios relacionados, entre ellos noticias sobre la industria cinematográfica y sus producciones.

\section{Cinecita (http://membres.lycos.fr/cinecita)}

Este recurso digital ofrece enlaces a contenidos cinematográficos esencialmente documentales de producción fílmica tanto española como latinoamericana: bases de datos, revistas, buscadores, filmotecas, estudios, etcétera. Ofrece los contenidos también en francés. Su principal inconveniente es que no tiene información especialmente actualizada.

\section{TDFilm: The Definitive Online Film Resource (www.tdfilm.com)}

Es un directorio británico que aporta enlaces a más de 15000 webs relacionadas con el cine y clasificadas por tema: películas, actores, directores, industria, festivales, bandas sonoras, entre otros.

\section{La documentación en publicidad}

La documentación es aplicable en la investigación publicitaria en sus tres vertientes: la investigación socioeconómica, la investigación de medios y la investigación de los mensajes publicitarios.

a) En el primer caso se encuentran todos los trabajos que, bajo una perspectiva de estudio multidisciplinar (en los que se detallan factores de tipo socioeconómico, sociológico, psicológico, etcétera), analizan el hecho publicitario. Así favorecen el conocimiento de la realidad publicitaria y de sus efectos en la sociedad, creando un marco de referencia adecuado.

b) La documentación también debiera estar presente en la investigación de medios, cuyo objetivo es el conocimiento de los mismos. Presenta diferentes subdivisiones: la investigación de la difusión (realización de auditorías o paneles de consumidores y establecimientos), la investigación de audiencias (encuestas y paneles, las audimetrías, donde destacan el EGM, el EGA y Sofres), la investigación sobre la distribución de los anuncios, sobre la inversión publicitaria y, finalmente, la investigación sobre el contenido de los medios, donde se observan sistemáticamente, se registran y se almacenan los anuncios con la intención de separar el contenido publicitario en cada medio, analizar y clasificar los contenidos informativos $\mathrm{y}$, en último lugar, identificar, registrar y analizar la publicidad existente en los diferentes medios. 
c) La investigación sobre el mensaje publicitario se preocupa del estudio del mensaje desde el momento de su concepción hasta el control de los efectos, agrupados habitualmente bajo las denominaciones de pretests y posttests.

Hay otras facetas: desde las mejoras en los briefings y contrabriefings hasta el descubrimiento de nuevos "lugares" de negocio o la creación publicitaria, ya sea en funciones de asesoramiento o en el marco del proceso productivo (a modo de ejemplo, las empresas que gestionan imágenes que luego aparecerán en los anuncios).

En la actualidad, los avances tecnológicos están complicando de forma relevante el mundo publicitario. De forma paulatina las agencias se están introduciendo en la Red. Mientras, Internet se convierte en otro medio, en un medio con una complejidad evidente. Así, el control y la medición de las audiencias y sus posibles aplicaciones se convierten en las primeras cuestiones que deben ser resueltas. En este sentido, las dos grandes áreas de investigación que emergen son los estudios de segmentación y los estudios del mensaje, por lo que, bien de forma directa o bien de modo colateral, se requieren recursos informativos y fórmulas de tratamiento de la información. El especialista debe estar atento al desarrollo de los acontecimientos. Encontraremos equipos multidisciplinares de trabajo con los consiguientes problemas de competencia entre informáticos, creativos y especialistas en información. También se generalizarán los proyectos virtuales, las interfaces tridimensionales, fórmulas intermedias de comunicación entre los editores y los anunciantes, así como promociones digitales de productos.

Serán los criterios comerciales los que dirijan todos los recursos informativodocumentales que estén presentes en puntos como el análisis de la adecuación de Internet a los negocios o en la definición del público objetivo, sin olvidar los criterios para el diseño web o el apoyo a las promociones y a la gestión.

Además de seguir necesitándose documentación para la elaboración de productos publicitarios, surgen nuevas funciones y tareas, como pueden ser la colaboración en la creación de sitios, no ya desde el punto de vista creativo sino desde la generación de formas activas de almacenamiento y recuperación de información mediante conocimientos como la configuración discursiva publicitaria; todo esto en un contexto revolucionario donde la división entre información y publicidad puede quedar diluida y donde se asistirá a las presentaciones de canales especializados en la televisión o en Internet. Entre los valores que aporta la documentación a la publicidad podemos destacar los siguientes: $a$ ) en el campo de la planificación de campañas, el conocimiento de la difusión y audiencia de los medios; $b$ ) en el campo de las relaciones públicas y la comunicación corporativa, argumentos sólidos para conseguir clientes, para elaborar los comunicados públicos de las empresas y para conocer opiniones generadas en torno a la empresa representada. 


\subsection{Fuentes y recursos virtuales}

Las fuentes de información documental facilitan la toma de decisiones sobre la inserción de publicidad en los distintos medios, con el objetivo final de obtener la máxima rentabilidad posible de las inversiones publicitarias. Hemos de destacar las siguientes fuentes para el mercado publicitario:

a) Sobre difusión de los medios impresos y electrónicos:

\section{OJD: Oficina de Justificación de la Difusión (http://www.ojd.es)}

Es una organización sin ánimo de lucro fundada en 1964 cuyo objetivo principal consiste en "obtener y facilitar información útil y puntual de la difusión y distribución de las publicaciones periódicas así como de los medios electrónicos de comunicación y la televisión digital para uso de anunciantes, agencias de publicidad, editores y demás personas o entes interesados". Controla la tirada y difusión de más de 600 publicaciones (impresas y electrónicas) y cualquier publicación periódica puede someterse voluntariamente a su control.

b) Relativas a las audiencias de los diferentes medios (estudian cuántos y cómo son los individuos expuestos a los medios de comunicación), destacan AIMC, que se encarga de medir audiencias mediante encuestas, y Sofres, cuya finalidad es medir audiencias, en este caso con audímetros.

AIMC (http://www.aimc.es).

AIMC investiga, mide y controla las audiencias de medios de comunicación, elabora el Estudio General de Medios (EGM) y estudia el comportamiento de la población con respecto al consumo de distintos medios de comunicación con el método de la entrevista personal, así como con la elaboración del estudio de carácter anual, compuesto por varias oleadas por meses. Se trata del popular Estudio General de Medios (EGM), envuelto en una reciente polémica protagonizada por la cadena COPE.

La muestra del EGM alcanza a unos 40000 individuos y en el cuestionario se incluyen datos sociodemográficos, hábitos de la audiencia, los medios estudiados (prensa, radio, cine, televisión, etcétera), la audiencia del último periodo y diferentes aspectos cualitativos sobre los consumidores-receptores de medios, entre otras cuestiones.

Sofres Audiencia de Medios (http://www.sofresam.com)

Características del panel de Sofres: la muestra es permanente para individuos de más de cuatro años, de viviendas principales; en torno a los 3000 hogares son los que tienen audímetros. Los datos proporcionados por el audímetro son los que siguen:

- Qué días y a qué horas se enciende o apaga el televisor.

- Qué miembro de la familia o invitado lo enciende.

Scire. $12: 2$ (jul.-dic. 2006) 165-175. ISSN 1135-3716. 
- Qué canal sintoniza.

- Qué cambios se producen (zapping).

- Qué uso se le está dando al televisor: vídeo, ordenador, antena, etcétera.

El Departamento de Minutado y Control de Programas e Inserciones Publicitarias controla todos los programas y anuncios emitidos por las cadenas de televisión sometidas a análisis. Dichos datos son complementarios a los obtenidos por los mencionados aparatos de medición conocidos con el nombre de audímetros.

c) Sobre contenidos e inversiones publicitarias en los medios:

\section{InfoAdex (http://www.infoadex.es)}

Realiza el control de la publicidad en España y analiza los spots publicitarios insertados en medios de comunicación. La base de datos del mismo nombre contiene más de cinco millones de anuncios controlados anualmente. Realiza informes sobre las inversiones realizadas por medios, mercados, anunciantes, etcétera. Destaca su publicación anual, en la que se expone la información derivada del acceso a las bases de datos de creatividad publicitaria, el seguimiento de campañas y patrocinios, el control de la competencia, el estudio de la inversión publicitaria en España tanto en medios convencionales como en soportes no convencionales y el estudio de agencias y centrales, como indicadores más destacables. Con ello, la información analizada por InfoAdex nos habla sobre el producto anunciado y su marca, el sector comercial al que pertenece, la posición que ocupa en el bloque publicitario y el tipo de publicidad que supone.

\section{Conclusiones}

Los profesionales de la información y la comunicación disponen de herramientas alojadas en Internet con las que realizar labores de documentación de cara a sus trabajos profesionales. La oferta de contenidos tanto gratuitos como de pago ha ido aumentando a lo largo de los años, pero el principal problema sigue siendo la falta de actualización de los sitios web, y en algunos casos la poca calidad o dudosa fiabilidad de las informaciones y los recursos ofrecidos. Esta constatación confirma que la Red de Redes supone una gran ayuda para los profesionales, si bien no se puede considerar en absoluto la panacea para todos los problemas o las necesidades concretas, tanto para la prensa como para el sector audiovisual y para la publicidad y las relaciones públicas.

De ahí que las fuentes digitales supongan una ayuda que no evita la conveniencia, cuando no la imperiosa necesidad, de acudir a otro tipo de fuentes tradicionales tanto estrictamente documentales como institucionales y personales con las que tener un trato del que pueda derivarse una mejor práctica profesional en sectores laborales tan complejos y cambiantes como los estudiados en el presente trabajo.

Scire. 12 : 2 (jul.-dic. 2006) 165-175. ISSN 1135-3716. 
Al mismo tiempo, muchos de los recursos digitales evaluados permiten comprobar que el sector de la información, la comunicación y la documentación presenta grandes convergencias tanto temáticas como de perfil profesional, algo que, aunque siempre haya sido así, hoy presenta unos niveles de proximidad o desdibujamiento entre los ámbitos de la información, la publicidad y el entretenimiento particularmente altos.

\section{Referencias}

Codina, Lluís (1997). Cómo funcionan los servicios de búsqueda en Internet: un informe especial para navegantes y creadores de información (partes I y II). // IWE. 6:5 (1997) 22-27 y 6:6 (1997) 18-26.

García Gutiérrez, Antonio (ed.) (1999). Introducción a la documentación informativa y periodística. Sevilla: MAD, 1999.

García Jiménez, Antonio (1999). La documentación de la publicidad y de las relaciones públicas. // García Gutiérrez, A. (ed.). Introducción a la Documentación Informativa y Periodística. Sevilla: MAD, 1999. 487-509.

Gómez Muñoz, Borja (2005). Publicidad interactiva en España. // Pérez-Ugena Coromina, Álvaro; Utray Delgado, Francisco. TV digital e integración: ¿TV para todos? Madrid: Dykinson: Universidad Rey Juan Carlos, 2005.

López Hernández, Ángeles (2003). Introducción a la documentación audiovisual. Carmona (Sevilla): SyC, 2003.

López Yepes, Alfonso (1993). La documentación multimedia: el tratamiento automatizado de la información periodística, audiovisual y publicitaria. Salamanca: Universidad Pontificia, 1993.

López Yepes, José (2006). Manual de ciencias de la documentación. Madrid: Pirámide, 2006.

Marcos Recio, Juan Carlos (1999). La documentación electrónica en los medios de comunicación. Madrid: Fragua, 1999.

Marcos Recio, Juan Carlos (coord.); García Jiménez, Antonio; Nuño Moral, M. ${ }^{a}$ Victoria (2004). Gestión de la documentación en la publicidad y en las relaciones públicas. Madrid: Síntesis, 2004.

Moreiro, José Antonio (coord.) (2000). Manual de documentación informativa. Madrid: Cátedra, 2000.

Ruiz Mantilla, J. (2005). Babel en la pantalla del ordenador: el anuncio de que Google volcará 15 millones de libros en la red pone en guardia al mundo editorial. // El País. (10 de abril de 2005) 40-41.

Scire. $12: 2$ (jul.-dic. 2006) 165-175. ISSN 1135-3716. 